\title{
Soldering Reactions between In49Sn and Ag Thick Films
}

\author{
M.D. CHENG, S.S. WANG, and T.H. CHUANG \\ Department of Materials Science and Engineering, National Taiwan University, Taipei 106, Taiwan
}

The interfacial reactions between In49Sn solders and Ag thick films at temperatures ranging from $200^{\circ} \mathrm{C}$ to $350^{\circ} \mathrm{C}$ have been studied. The intermetallic compound formed at the $\mathrm{Ag} / \mathrm{ln} 49 \mathrm{Sn}$ interface is $\mathrm{Ag}_{2} \mathrm{I} \mathrm{n}$ envel oped in a thin layer of Agl $n_{2}$. Through the measurement of the thickness decrease of Ag thick films, it has been determined that the reaction kinetics of $\mathrm{Ag}_{2} \mathrm{In}$ has a linear relation to reaction time. Morphology observations indicated that the linear reaction of $A g_{2} I n$ was caused by the floating of $\mathrm{Ag}_{2} \mathrm{I} \mathrm{n}$ into the In49Sn sol der as a result of the In49Sn solder penetrating into the porous Ag thick film. A sound joint can be obtained when a sufficient thickness of the Ag thick film (over $19.5 \mu \mathrm{m}$ ) reacts with the In49Sn solder. In this case, the tensile tested specimens fracture in the In49Sn matrix.

Key words: In49Sn solders, Ag thick films, intermetallic compounds, bonding strengths

\section{INTRODUCTION}

For most interfacial reactions during the soldering process, the growth kinetics of intermetallic compounds formed at the liquid solder/substrate interface has been shown to be diffusion controlled, ${ }^{1-5}$ following a parabolic law. However, in a study by Kim et al., ${ }^{6}$ it was found that, accompanied with the formation of a scallop-shaped $\mathrm{Cu}_{6} \mathrm{Sn}_{5}$ intermetallic compound at the interface between the liquid Pb63Sn solder and the $\mathrm{Cu}$ substrate, the growth rate had a ratio of (time) ${ }^{1 / 3}$, which could be explained by the ripening reaction of $\mathrm{Cu}_{6} \mathrm{Sn}_{5} .{ }^{7}$ On the other hand, Tu and Thompson ${ }^{8}$ found that the $\mathrm{Cu}_{6} \mathrm{Sn}_{5}$ intermetallic compound grew linearly at the interface between thin $\mathrm{Cu}$ and $\mathrm{Sn}$ films. In that case, the release of $\mathrm{Cu}$ atoms from the $\mathrm{Cu}$ film into Sn was considered as the ratelimiting step for such a linear growth. Bader and Gust ${ }^{9}$ studied the growth kinetics of solid-liquid interdiffusion, bonding the $\mathrm{Cu} / \mathrm{Sn} / \mathrm{Cu}$ intermetallic compounds into a thin film couple. The $\mathrm{Cu}_{6} \mathrm{Sn}_{5}$ intermetallic compound grew in the ratio of (time) ${ }^{n}$, where $n$ was 0.20 and 0.25 for the temperatures of $240^{\circ} \mathrm{C}$ and $300^{\circ} \mathrm{C}$, respectively. According to Bader and Gust's explanation, the nonparabolic growth kinetics of $\mathrm{Cu}_{6} \mathrm{Sn}_{5}$ at the $\mathrm{Cu} / \mathrm{Sn}$ interface occurred when $\mathrm{Cu}$ and $\mathrm{Sn}$ atoms diffused

(Received J une 21, 2001; accepted October 18, 2001) through the grooves between the $\mathrm{Cu}_{6} \mathrm{Sn}_{5}$ crystallites. Concurrent with the growth of $\mathrm{Cu}_{6} \mathrm{Sn}_{5}$, the grooves would become narrower, and the diffusion of $\mathrm{Cu}$ and $\mathrm{Sn}$ atoms would slow down. The nonparabolic growth of intermetallic compounds was also reported by Howard et al. ${ }^{10}$ for interfacial reactions between aluminum and certain transition-metal thin films, such as $\mathrm{Zr}, \mathrm{Hf}$, and $\mathrm{Ta}$. In this case, however, the intermetallic compounds that formed at the interfaces of $\mathrm{Al} / \mathrm{Cr}, \mathrm{Pt}, \mathrm{Co}$, and $\mathrm{Ti}$ thin films followed a parabolic growth law. To explain this phenomenon, Howard et al. followed a relationship between the growth kinetics and melting points of intermetallic compounds. They showed that the higher melting-point compounds $\left(\mathrm{HfAl}_{3}, \mathrm{ZrAl}_{3}\right.$, $\mathrm{TaAl}_{3}$, etc.) were formed at the interfaces of $\mathrm{Al} / \mathrm{Zr}$, $\mathrm{Hf}$, and Ta; resulting in lower lattice diffusivity. Thus, the diffusing atoms selectively penetrated the grain boundaries with slight lattice diffusion, which caused these higher melting-point compounds to grow at a rate proportional to (time) ) $^{1 / 4}$.

Owing to their low melting points, InSn solders have been widely used in bonding the recycled sputtering targets with their back plates while Ag has been regarded as a popular sputtering material. In previous work by one of the authors, ${ }^{10}$ interfacial reaction between the liquid In49Sn solder and the Ag plate was studied. ${ }^{9}$ It was found that a scallop- 
shaped $A g_{2} I n$ phase enveloped in an $A g l n_{2}$ thin outer layer appeared at the InSn/Ag interface. The growth kinetics of $A g_{2} I n$ followed the parabolic law and was diffusion controlled. Since sintered Ag thick films possess a different microstructure from the rolling Ag plates, it should make sense to further compare the interfacial reaction of the InSn/Ag thick film with that of the InSn/Ag plate. As it turns out, the result is interesting, showing that the reaction kinetics in the present case has changed to a linear relation. The mechanism of such a linear relation between In49Sn solders and Ag thick films has been clarified through observations of the intermetallic compounds formed during the soldering reaction. In addition, the bonding strengths of the solder joints in relation to the reacted thickness of the Ag thick film are also investigated.

\section{EXPERIMENTAL}

The surface of an alumina substrate was coated with silver paste using a screen printer (composition: Ag 75-80\%, glass $1-5 \%$, resin $1-5 \%$, terpineol 5-10\%, and diethyl phthalate 5-10\%). Specimens were first heated at $150^{\circ} \mathrm{C}$ for $10 \mathrm{~min}$. and then sintered at $850^{\circ} \mathrm{C}$ for $10 \mathrm{~min}$. in an air furnace. After sintering, the specimens were cooled to room temperature. The sintered Ag thick film on the alumina substrate possessed a thickness of $70 \pm 2 \mu \mathrm{m}$ and low porosity, as shown in Fig. 1. The In49Sn solder with a melting point of $120^{\circ} \mathrm{C}$ was prepared by vacuum melting into an ingot and homogenized at $100^{\circ} \mathrm{C}$ for 50 hours. The microstructure of such a homogenized eutectic In49Sn solder is composed of coarse islands in the Sn-rich phase and a matrix in the In-rich phase. Afterward, the In49Sn ingot was rolled into a $0.2-\mathrm{mm}$-thick foil. For the study of interfacial reactions, the solder foil was cut to the same size as the $\mathrm{Ag} / \mathrm{Al}_{2} \mathrm{O}_{3}$ substrate, inserted and sandwiched in between two $\mathrm{Ag} / \mathrm{Al}_{2} \mathrm{O}_{3}$ substrates, and then heated in an infrared furnace under a vacuum of $10^{-3}$ torr. To eliminate the oxidation factor in soldering, flux was applied before testing. For the measurements of bonding strengths of the solder joints, both sides of the sandwiched specimens were

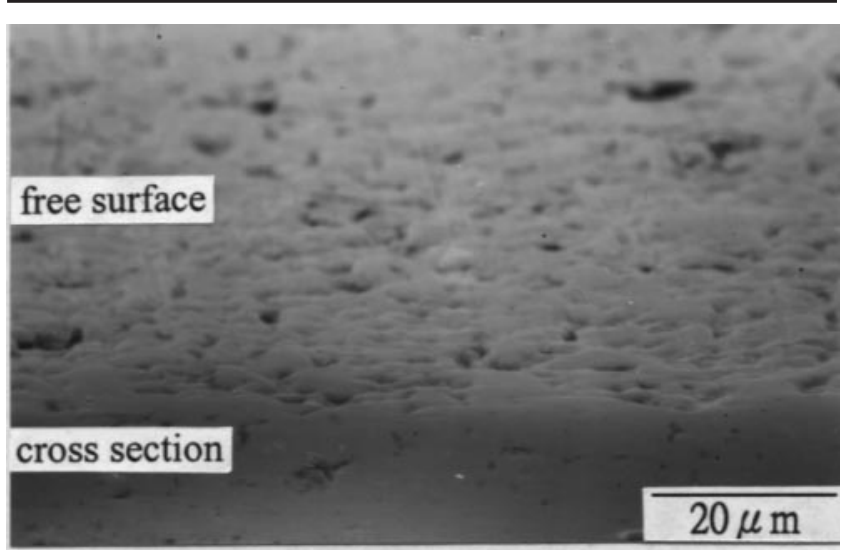

Fig. 1. Tilt image to show the cross section and free surface of the as-sintered Ag thick film. gripped in the tensile testing machine, as shown in Fig. 2. The tensile tests were conducted at a crosshead speed of $20 \mathrm{~mm} / \mathrm{min}$.

Soldering reactions took place at temperatures ranging from $200^{\circ} \mathrm{C}$ to $350^{\circ} \mathrm{C}$ for various periods of time. After reaction, the soldered specimens were cross sectioned, ground with $\mathrm{SiC}$ paper, polished with $1 \mu \mathrm{m}$ and $0.3 \mu \mathrm{m} \mathrm{Al}{ }_{2} \mathrm{O}_{3}$ powders, and observed by scanning electron microscopy. For kinetics analysis, the average thickness was obtained from measurements of at least five spots of the layers. The compositions of the intermetallic compounds formed during reaction were analyzed by energy dispersive x-ray spectroscopy (EDS).

\section{RESULTS AND DISCUSSION}

During the soldering reaction between In49Sn and the $\mathrm{Ag}$ thick film, a scallop-shaped $\mathrm{Ag}_{2} \mathrm{I}$ intermetallic phase is formed at the In49Sn/Ag interface. Along the reaction front of $A g_{2} I n$, a thin layer of Agl $n_{2}$ can be observed. The chemical compositions (wt.\%) of the $\mathrm{Ag}_{2} \mathrm{In}$ and $\mathrm{Agl} \mathrm{n}_{2}$ phases, as analyzed by

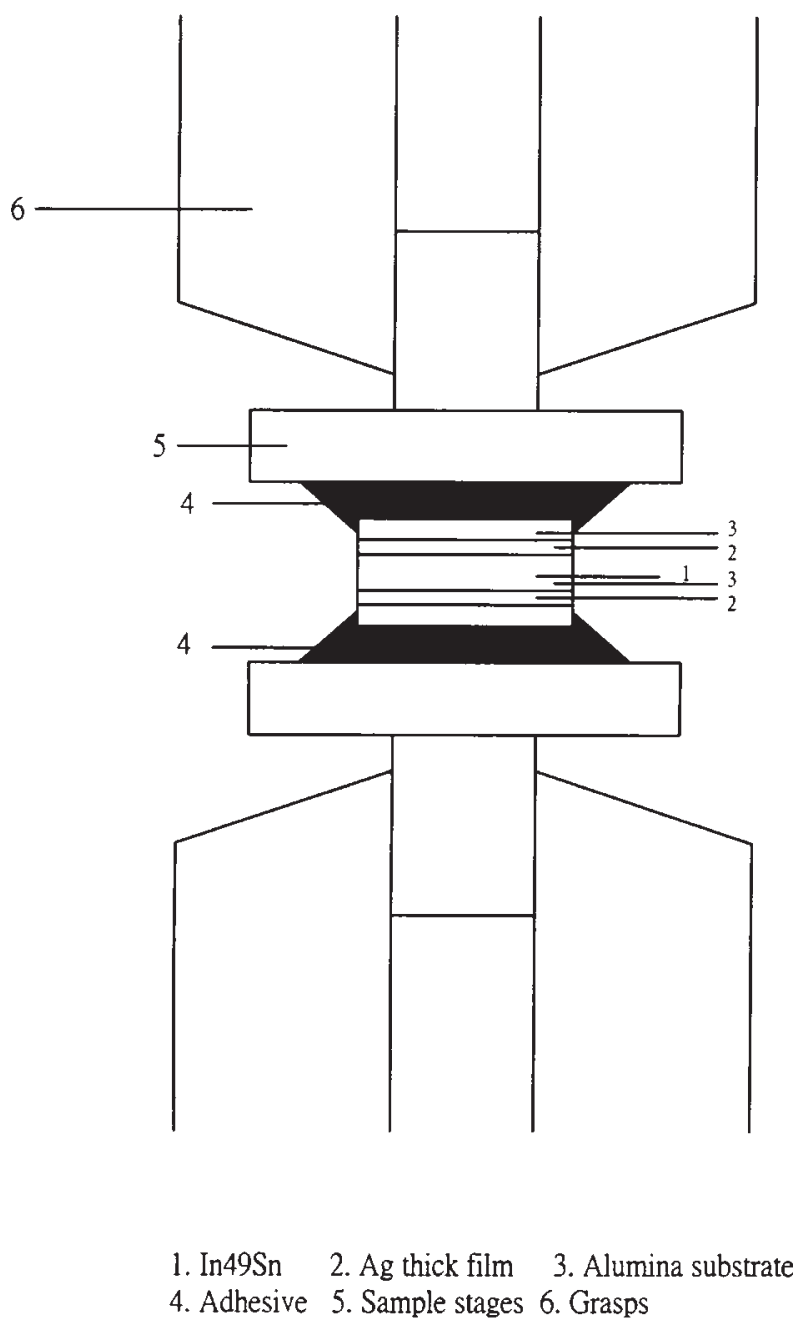

Fig. 2. Tensile test for the bonding strengths of the $\mathrm{Al}_{2} \mathrm{O}_{3} / \mathrm{Ag} /$ $\mathrm{In} 49 \mathrm{Sn} / \mathrm{Ag} / \mathrm{Al}_{2} \mathrm{O}_{3}$ solder joints. 
EDS, are Ag:In:Sn = 67.2:30.2:2.6 and 32.3:61.5:6.2. $\mathrm{The}_{\mathrm{Ag}} \mathrm{I} \mathrm{n}$ intermetallic compound grows with an increase in reaction time (Fig. 3) and temperature (Fig. 4). The thickness of the Ag film decreases with time and temperature, and the liquid solder filters into the pores of the as-sintered Ag thick film to form intermetallic branches, as shown in Fig. 5. These intermetallic branches, as analyzed by EDS, are the $A g_{2} I n$ phase, accompanied by small $A g l n_{2}$ granules. With longer reaction time, a large number of crevices and cavities appear at the boundaries of the $\mathrm{Ag}_{2}$ In crystallites (Fig. 6). In some cases, the $\mathrm{Ag}_{2} \mathrm{In}$ intermetallic compounds cleave transgranularly into two pieces, as shown in Fig. 7. These broken $\mathrm{Ag}_{2} \mathrm{In}$ intermetallic compounds splinter away from the Ag thick film and float into the liquid solder (Fig. 8). In Fig. 8, an initiated crack can also be observed near the interface between $A g_{2} I n$ and the $\mathrm{Ag}$ thick film. Because a considerable amount of $\mathrm{Ag}_{2}$ I $\mathrm{n}$ drifts away from the In49Sn/Ag interface, the remaining $\mathrm{Ag}_{2} \mathrm{I}$ intermetallic layer at the interface between the In49Sn solder and the Ag thick film has a thickness of 8-15 $\mu \mathrm{m}$. The total reaction kinetics of spalling and nonspalling intermetallic compounds during the soldering reaction between the In49Sn solder and the Ag thick film is, thus, indirectly ascertained from the thickness decrease $(\Delta X)$ of the Ag film. In this case, the thickness of the nonspalling $\mathrm{Ag}_{2} \mathrm{I} \mathrm{n}$ attached to the unreacted $\mathrm{Ag}$ film is excluded from the measurements. The slopes of the plots in Fig. 9 give the $n$ values of the kinetics relation: $\Delta X=$ $\mathrm{t}^{\mathrm{n}}$. The $\mathrm{n}$ values range from 1.04 to 1.15 , which implies a linear reaction of the intermetallic compounds at the interface between the liquid In49Sn solder and the thick Ag film. The result is different from that previously obtained from the soldering reaction between the liquid I n49Sn solder and plated Ag. This difference is attributed to the porosity of the Ag thick film, resulting in the In49Sn solder penetrating into the Ag thick film and increasing its reaction with $\mathrm{Ag}$. In addition, the spalling of $A g_{2} I n$ intermetallic compounds in this study is quite dominant over the growth of the nonspalling film, which should also yield a linear reaction, as evidenced by kinetics analysis. At the final stage of the soldering reaction, the $\mathrm{Ag}$ thick film will be exhausted, and cracking will occur at the interface between $\mathrm{Ag}_{2} \mathrm{In}$ and the alumina substrate. On certain locations where small quantities of the Ag thick film still linger on the alumina substrate, as shown in Fig. 10,
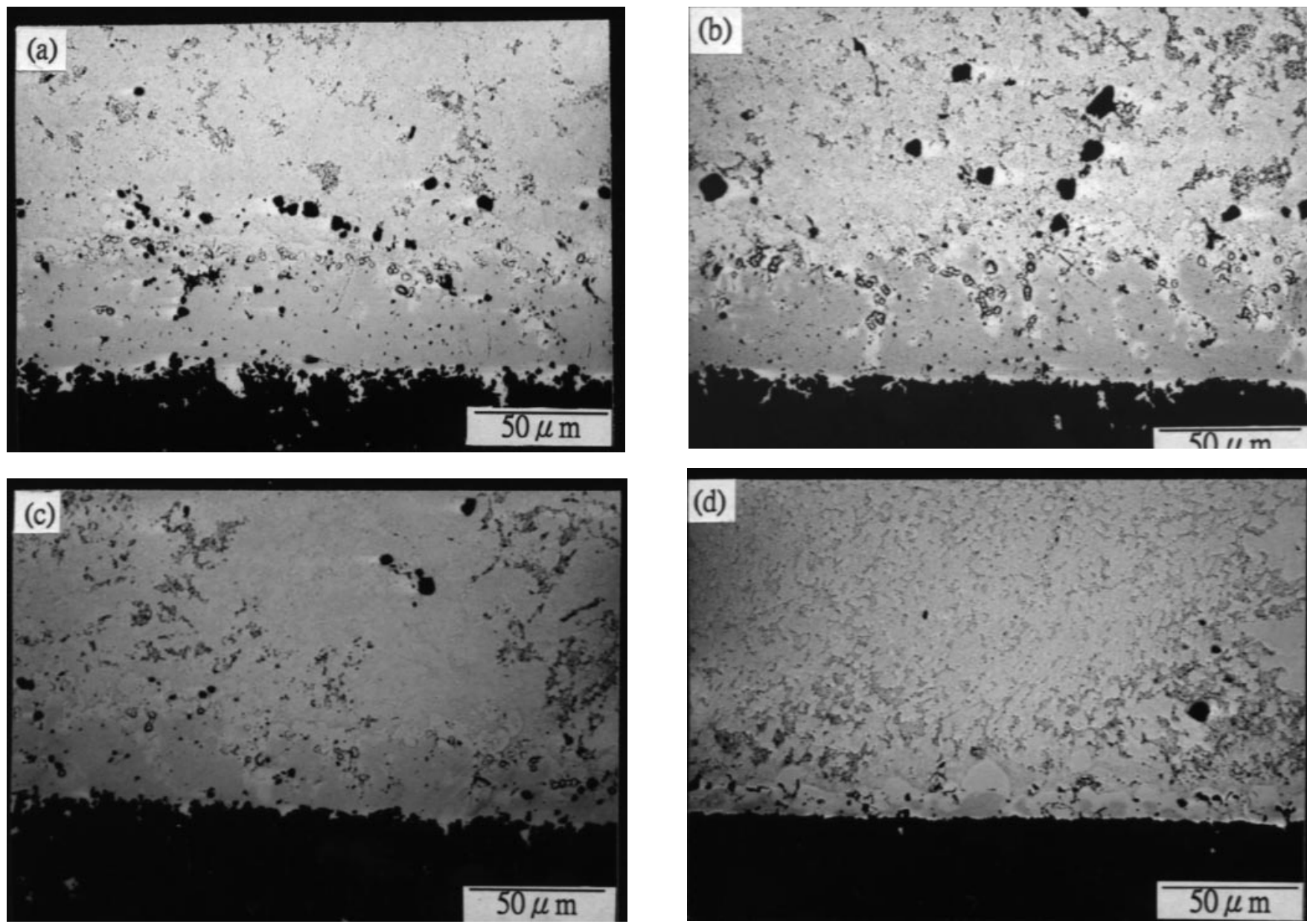

Fig. 3. Morphology of intermetallic compounds formed after soldering reaction between liquid In $49 \mathrm{Sn}$ and the Ag thick film at $200^{\circ} \mathrm{C}$ for various reaction times: (a) $10 \mathrm{~min}$., (b) $15 \mathrm{~min}$., (c) $30 \mathrm{~min}$., and (d) $60 \mathrm{~min}$. 

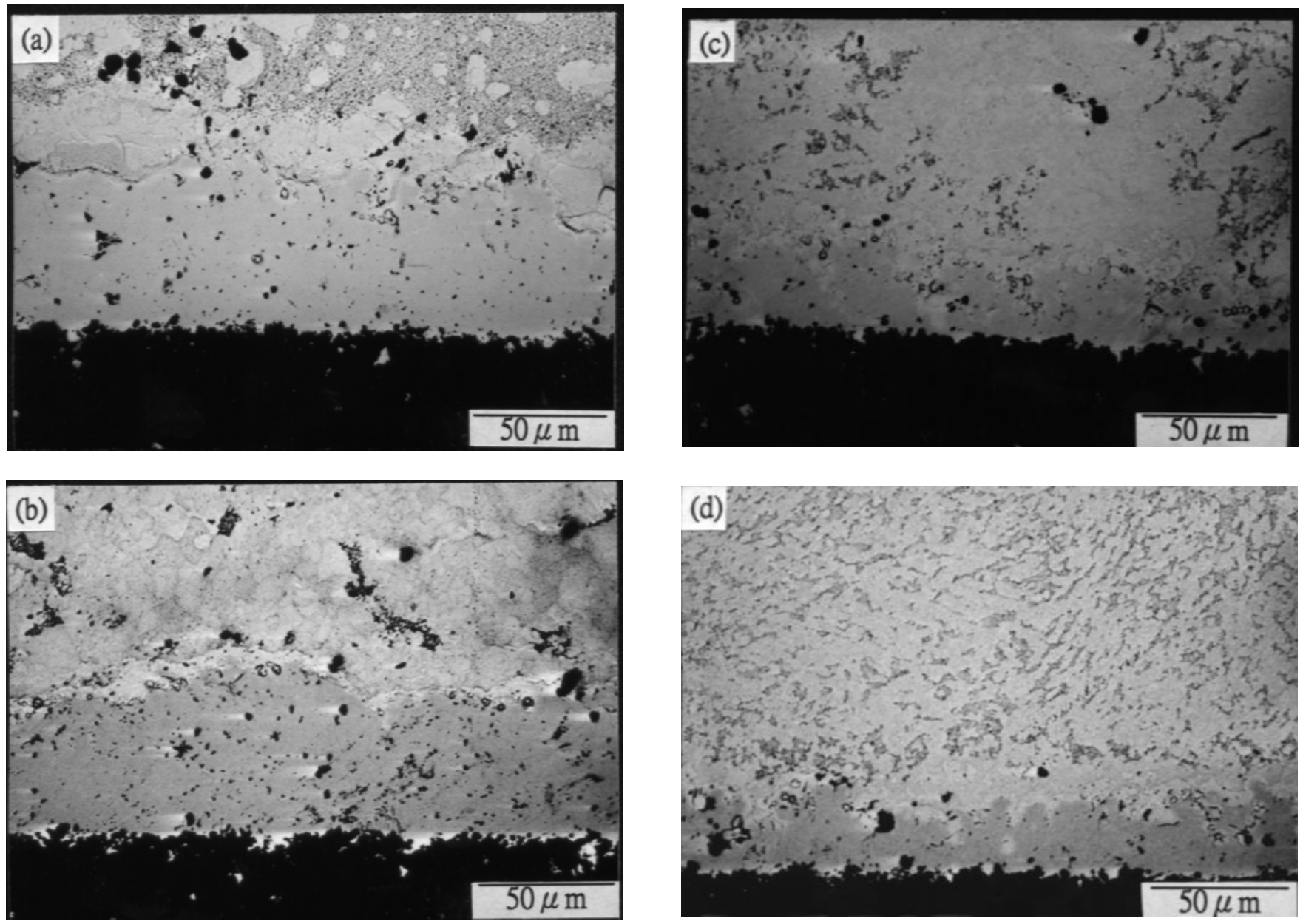

Fig. 4. Morphology of intermetallic compounds formed after soldering reaction between liquid In49Sn and the Ag thick film at various temperatures for 5 min.: (a) $200^{\circ} \mathrm{C}$, (b) $225^{\circ} \mathrm{C}$, (c) $250^{\circ} \mathrm{C}$, and (d) $275^{\circ} \mathrm{C}$

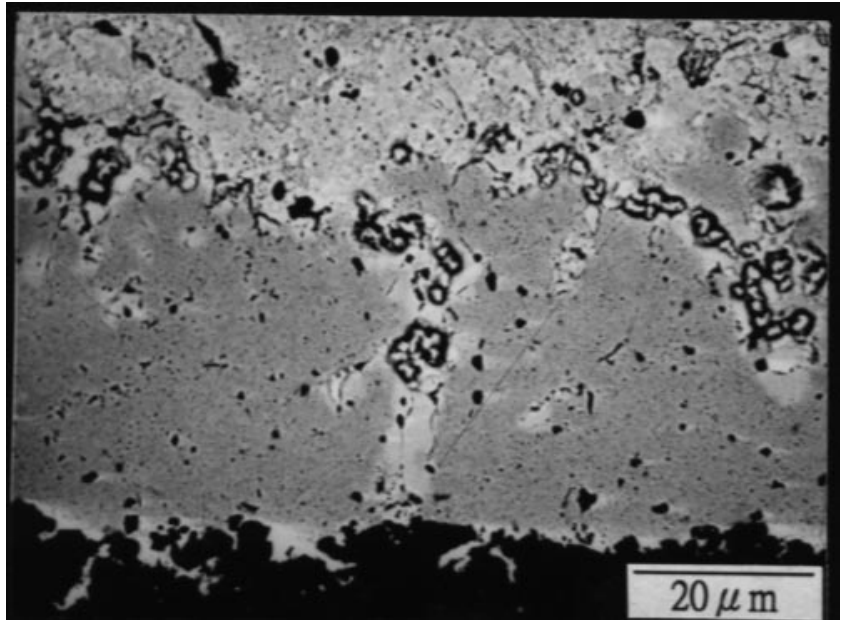

Fig. 5. Penetration of liquid In49Sn into the $\mathrm{Ag}$ thick film to form small particles of the $\mathrm{Agln}_{2}$ phase (soldering condition: $200^{\circ} \mathrm{C}, 15$ $\min$. .).

the crack propagates along the interface between $A g_{2} I n$ and the rest of the Ag thick film.

The tensile strengths of $\mathrm{Al}_{2} \mathrm{O}_{3} / \mathrm{Ag} / \mathrm{ln} 49 \mathrm{Sn} / \mathrm{Ag} / \mathrm{Al}_{2} \mathrm{O}_{3}$ joints, sol dered under various conditions, were measured, as listed in Table I, and plotted as a function of

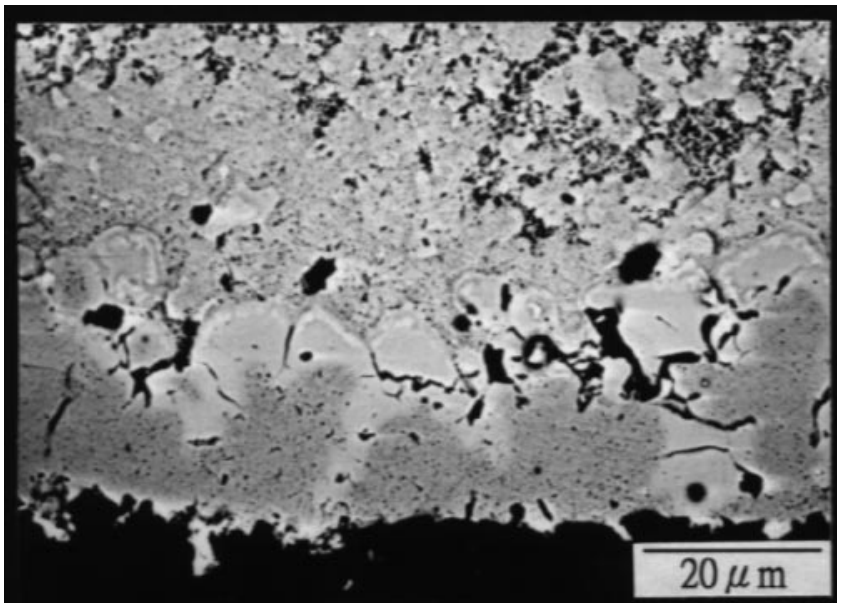

Fig. 6. The appearance of crevices or cavities between $\mathrm{Ag}_{2}$ In crystallites (soldering condition: $200^{\circ} \mathrm{C}, 30 \mathrm{~min}$.).

the thickness decrease $(\Delta \mathrm{X})$ of the Ag film (Fig. 11). At the early stage (lower temperatures and shorter durations), the reaction between In49Sn and the $\mathrm{Ag}$ thick film is insufficient to attain a satisfactory joint. Figure 12 shows that in this case the bonded specimens fracture along the interface between the 


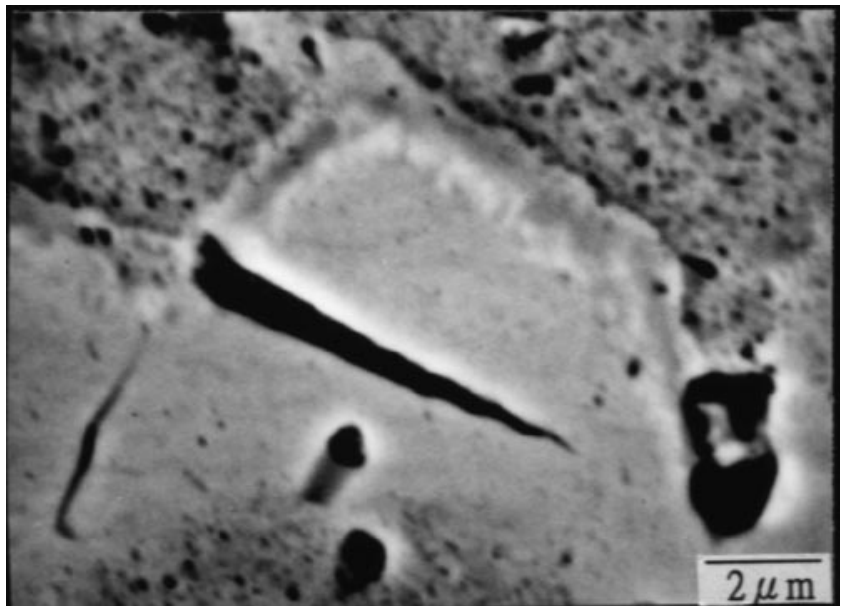

Fig. 7. The appearance of the transgranular crack in $\mathrm{Ag}_{2} \mathrm{In}$ intermetallic compounds (soldering condition: $200^{\circ} \mathrm{C}, 60 \mathrm{~min}$.).

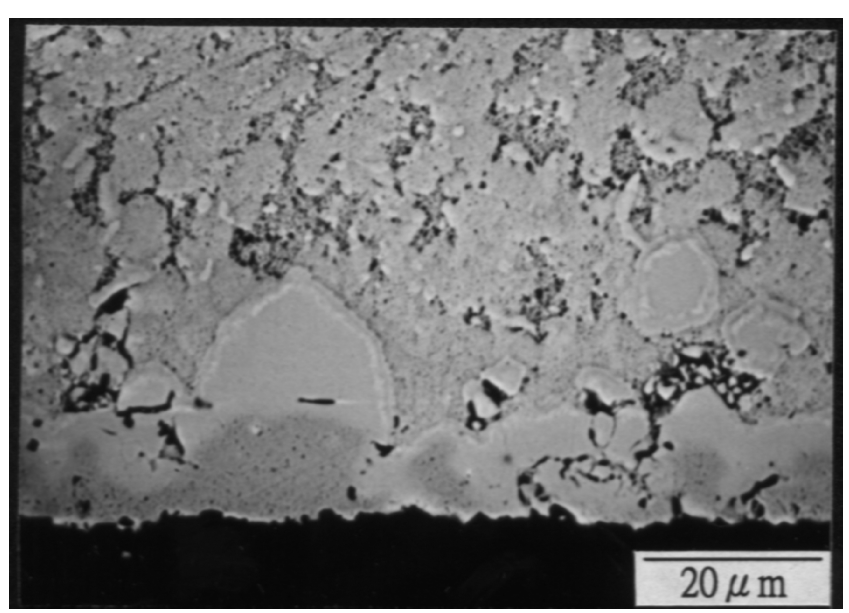

Fig. 8. Floating of $\mathrm{Ag}_{2}$ In intermetallic compounds into the In49Sn solder (soldering condition: $200^{\circ} \mathrm{C} 30 \mathrm{~min}$.).

In49Sn solder and the incomplete intermetallic layer. With respect to the In49Sn solder, fractography shows a dimpled appearance (Fig. 12a). The chemical composition, as analyzed by EDS, is Ag:In:Sn $=0.4: 60.3: 39.3$. However, on the part of the $\mathrm{Ag} / \mathrm{Al}_{2} \mathrm{O}_{3}$ substrate, the fractured surface is covered with $\mathrm{Ag}_{2} \mathrm{In}$ intermetallic compounds and a few In49Sn solder dimples, as shown in Fig. 12b. The EDS analyses show a chemical composition (wt.\%) of

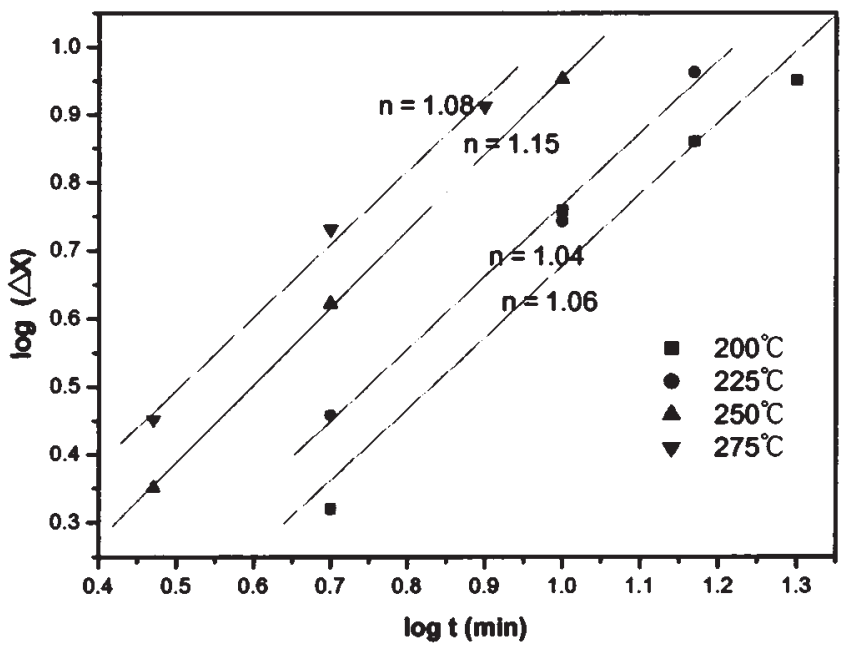

Fig. 9. Log plot of the thickness decrease $(\Delta X)$ of the $\mathrm{Ag}$ thick film as a function of the reaction time.

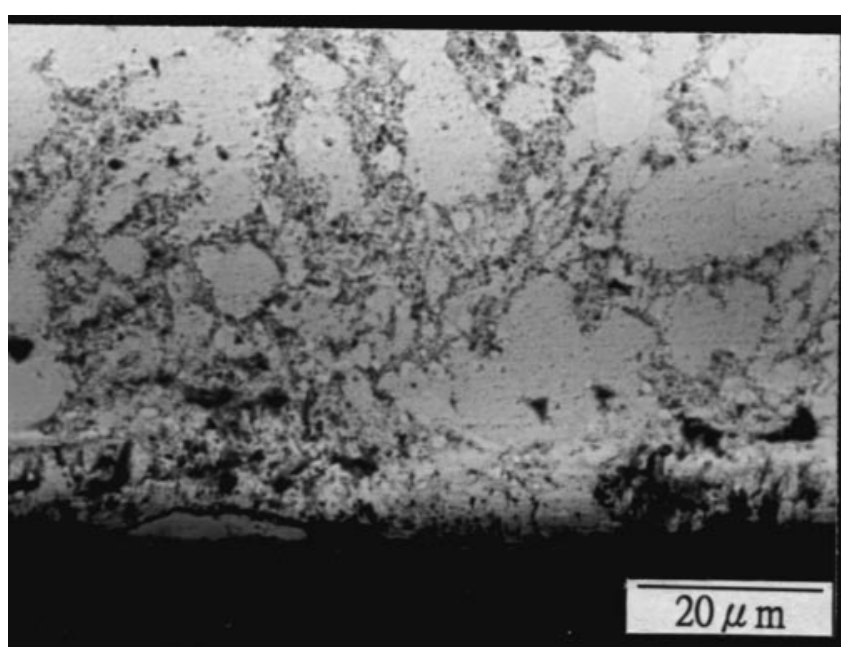

Fig. 10. Cracking appears at the interface between $\mathrm{Ag}_{2} \mathrm{In}$ and the alumina substrate when the $\mathrm{Ag}$ thick film is exhausted (soldering condition: $275^{\circ} \mathrm{C}, 15 \mathrm{~min}$.)

Ag:In:Sn = 54.1:36.7:9.2. After a sufficient amount of the Ag thick film $(\Delta \mathrm{X}>19.5 \mu \mathrm{m})$ has reacted with the In49Sn solder, the bonding strength increased to a value above the tensile strength of the In49Sn sol$\operatorname{der}\left(129.2 \pm 7.9 \mathrm{~kg} / \mathrm{cm}^{2}\right)$. Under these conditions, the $\mathrm{Al}_{2} \mathrm{O}_{3} / \mathrm{Ag} / \mathrm{In} 49 \mathrm{Sn} / \mathrm{Ag} / \mathrm{Al}_{2} \mathrm{O}_{3}$ joints fracture through

Table I. Bonding Strength and Fracture Locations of $\mathrm{Al}_{2} \mathrm{O}_{3} / \mathrm{Ag} / \mathrm{In} 49 \mathrm{Sn} / \mathrm{Ag} / \mathrm{Al}_{2} \mathrm{O}_{3} \mathrm{~J}$ oints Soldered under Various Conditions

\begin{tabular}{|c|c|c|c|}
\hline Soldering Conditions & Ag Thickness Decrease $(\mu \mathrm{m})$ & Bonding Strength $\left(\mathrm{kg} / \mathrm{cm}^{2}\right)$ & Fracture Locations \\
\hline $200^{\circ} \mathrm{C}, 5 \mathrm{~min}$. & 3.9 & 4.6 & Solder/I.M.* \\
\hline $225^{\circ} \mathrm{C}, 5 \mathrm{~min}$. & 11.1 & 12.8 & Solder/I.M. \\
\hline $200^{\circ} \mathrm{C}, 10 \mathrm{~min}$. & 19.5 & 129.6 & Solder \\
\hline $200^{\circ} \mathrm{C}, 15 \mathrm{~min}$. & 25.1 & 127.8 & Solder \\
\hline $200^{\circ} \mathrm{C}, 30 \mathrm{~min}$. & 39.5 & 134.3 & Solder \\
\hline $275^{\circ} \mathrm{C}, 5 \mathrm{~min}$. & 40.4 & 121.3 & Solder \\
\hline $200^{\circ} \mathrm{C}, 30 \mathrm{~min}$. & 57.0 & 133.2 & Solder \\
\hline $2000^{\circ}, 60 \mathrm{~min}$. & 64.9 & 45.8 & I.M. or I.M. $/ \mathrm{Al}_{2} \mathrm{O}_{3}$ \\
\hline
\end{tabular}

$*$ I.M. $=\mathrm{Ag}_{2} \mathrm{In}$ and $\mathrm{Agl} \mathrm{n}_{2}$ intermetallic compounds. 


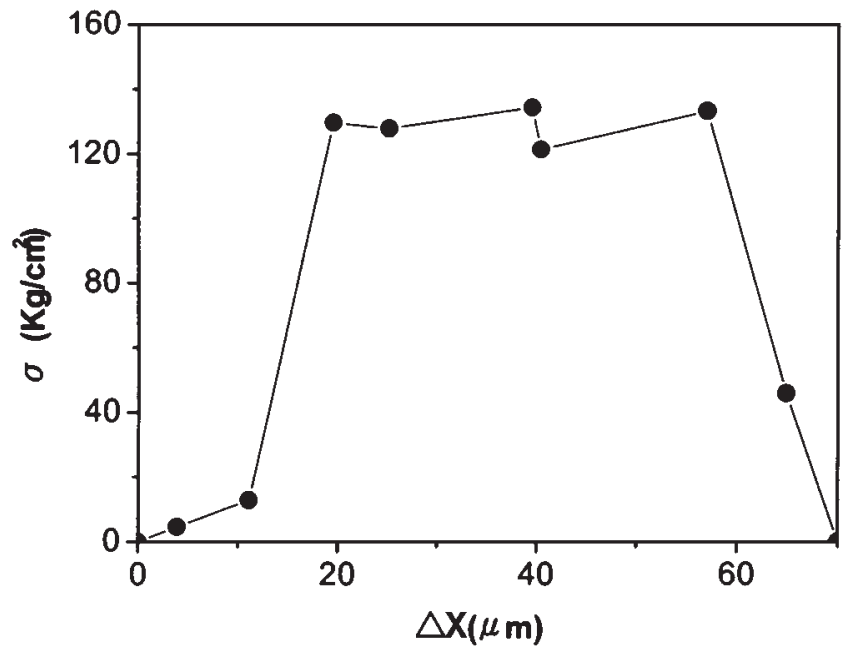

Fig. 11. Bonding strengths $(\sigma)$ of the $\mathrm{Al}_{2} \mathrm{O}_{3} / \mathrm{Ag} / \mathrm{ln} 49 \mathrm{Sn} / \mathrm{Ag} / \mathrm{Al}_{2} \mathrm{O}_{3}$ joints as a function of the thickness decrease $(\Delta \mathrm{X})$ of the $\mathrm{Ag}$ thick films.
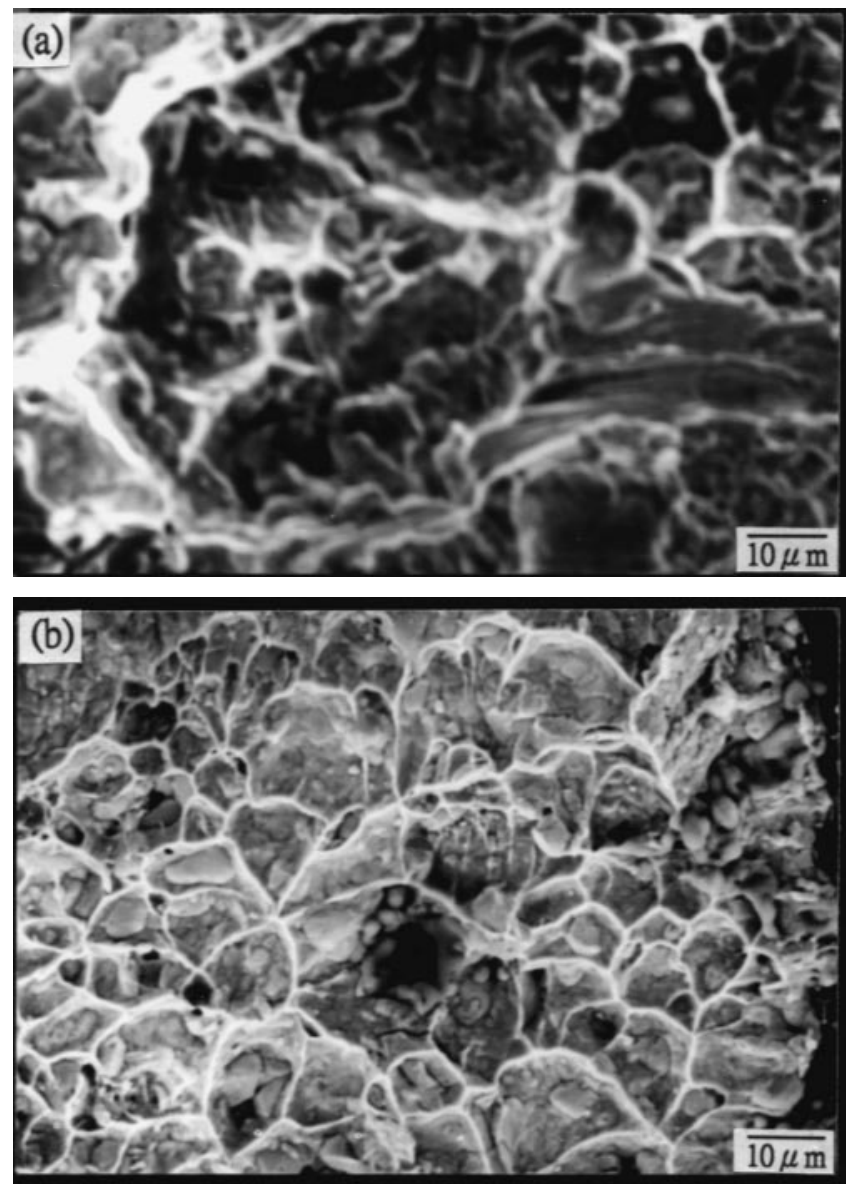

Fig. 12. Fractography of the $\mathrm{Al}_{2} \mathrm{O}_{3} / \mathrm{Ag} / \mathrm{ln} 49 \mathrm{Sn} / \mathrm{Ag} / \mathrm{Al}_{2} \mathrm{O}_{3}$ joints bonded at $225^{\circ} \mathrm{C}$ for 5 min.: (a) on the side of the In49Sn solder and (b) on the side of the $\mathrm{Ag} / \mathrm{Al}_{2} \mathrm{O}_{3}$ substrate.

the In49Sn solder matrix after tensile testing. Fractography of these solder joints reveals a dimpled appearance (Fig. 13). The EDS analyses of the fractured surfaces indicate that the chemical compositions (wt.\%) are similar (Ag: 0.8-2.0, In: 57.2-61.3, and Sn:

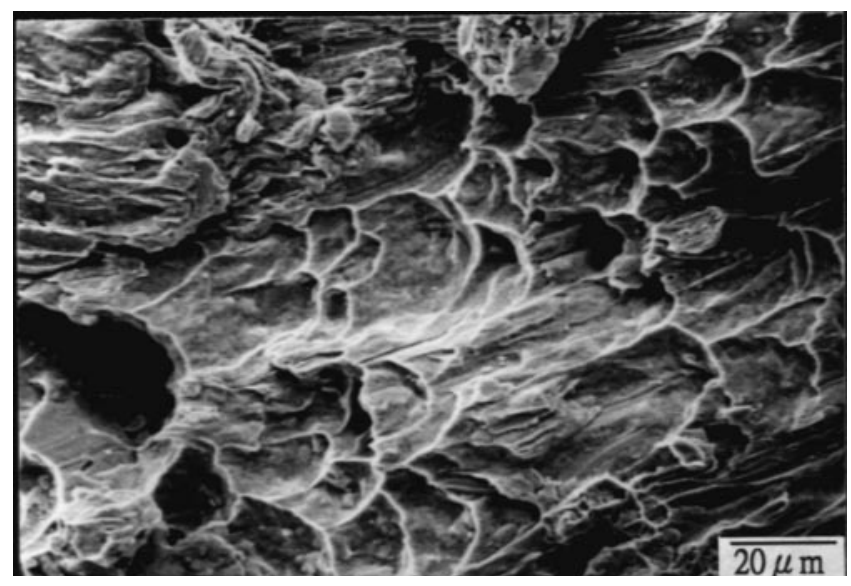

Fig. 13. A typical micrograph of the tensile fractured surfaces of $\mathrm{Al}_{2} \mathrm{O}_{3} / \mathrm{Ag} / \mathrm{ln} 49 \mathrm{Sn} / \mathrm{Ag} / \mathrm{Al}_{2} \mathrm{O}_{3}$ joints bonded at $200^{\circ} \mathrm{C}$ for $10 \mathrm{~min}$. Similar dimple fractographies appear at all sound joints in Table I.

37.2-40.1). In this case, the higher Ag content (shown in Fig. 13, compared with Fig. 12a) is attributed to the larger amount of $\mathrm{Ag}_{2} \mathrm{I}$ floating into the In49Sn solder. Such satisfactory joints can be obtained in all cases where the thicknesses of reacted Ag films are within a wide range between $19.5 \mu \mathrm{m}$ and $57.0 \mu \mathrm{m}$. It is well known that thick intermetallics cause the problem of brittle fracture in the soldered joints. However, the spalling of $\mathrm{Ag}_{2} \mathrm{In}$, in this study, keeps the thickness of the interfacial intermetallic layer within the range of 8-15 $\mu \mathrm{m}$ notwithstanding that a much larger amount of the Ag film has reacted with the In49Sn solder, which seems to constitute the cause for the survival of these overreacted Ag/ln49Sn/Ag joints. It is only as most of the Ag thick film is exhausted $(\Delta X>64.9$ $\mu \mathrm{m}$ ) that the bonding strength will drop drastically, as shown in Fig. 11. The tensile fractured specimens break either in the intermetallic layer (Fig. 14a) or along the interface between the intermetallic compound and the alumina substrate (Fig. 14b). In the former case, EDS analyses of the fractured surface show a chemical composition (wt.\%) of Ag:In = 75.7:24.3. In contrast, the chemical composition (wt.\%) of the fractured surface in the latter case (shown in Fig. 14b) is Al:Ag:In = 79.8:13.8:6.4, confirming that cracking takes place along the intermetallic compound/alumina interface.

\section{CONCLUSIONS}

$\mathrm{Ag}_{2}$ In intermetallic compounds are known to possess parabolic growth kinetics, as found by a previous study on the interfacial reactions between the liquid In49Sn solder and the Ag plate. ${ }^{11}$ However, when the substrate is transformed to an Ag thick film, reaction with the In49Sn solder exhibits the linear growth kinetics of the $\mathrm{Ag}_{2} \mathrm{In}$ intermetallic compounds. Such linear growth kinetics of $\mathrm{Ag}_{2} \mathrm{In}$ during the soldering reaction between In49Sn and the Ag thick film is attributed to the porosities of the sintered Ag thick film, as liquid In49Sn solders are channeled to penetrate into the Ag thick film accel- 

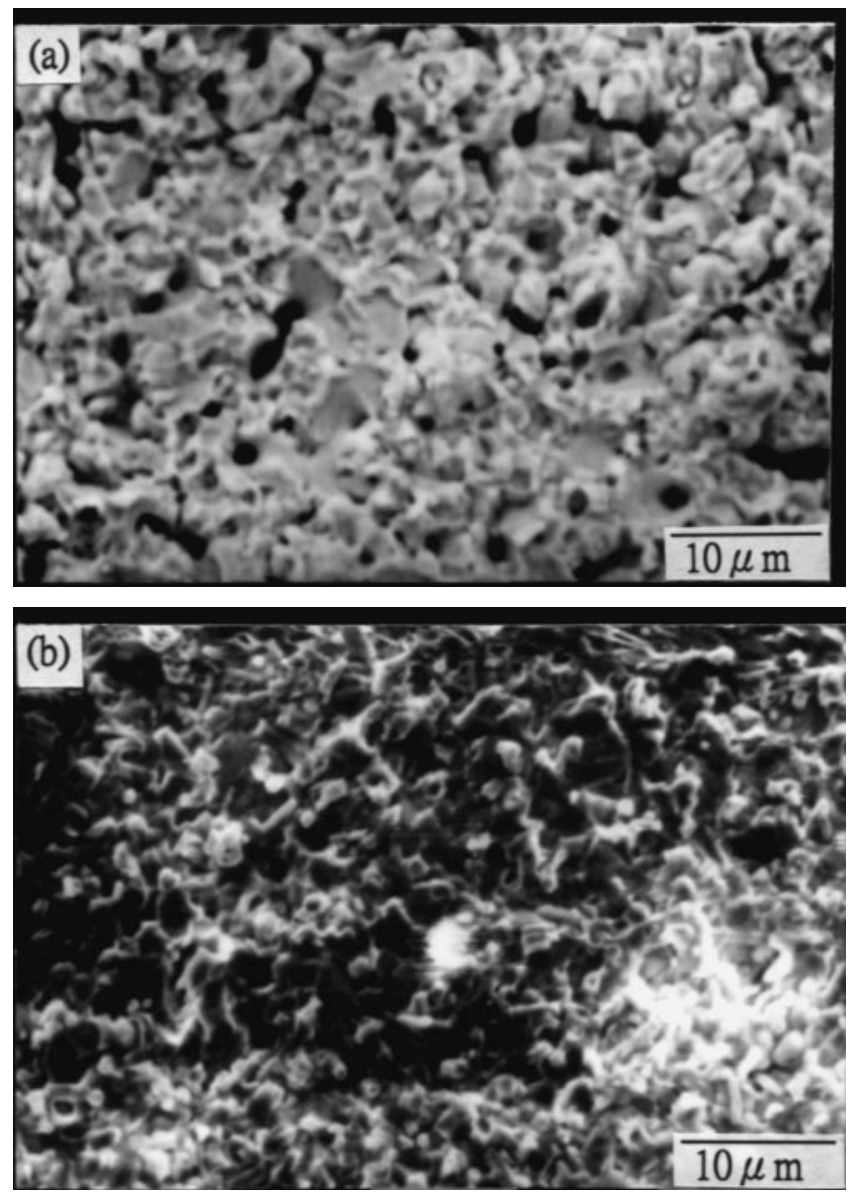

Fig. 14. Fractography of the $\mathrm{Al}_{2} \mathrm{O}_{3} / \mathrm{Ag} / \mathrm{ln} 49 \mathrm{Sn} / \mathrm{Ag} / \mathrm{Al}_{2} \mathrm{O}_{3}$ joints bonded at $200^{\circ} \mathrm{C}$ for 60 min.: (a) fracture location of the intermetallic compound and (b) fracture location at the intermetallic/alumina interface. erating the reaction. $\mathrm{Ag}_{2} \mathrm{In}$, the reaction product, is also found to break away from the Ag thick film and float into the In49Sn solder, which expedites such a soldering reaction. When sufficient $\mathrm{Ag}$ thick film (reaching the 19.5- $\mu \mathrm{m}$-thick par) has reacted with the In49Sn solder, a sound joint with a bonding strength of above $129.2 \mathrm{~kg} / \mathrm{cm}^{2}$ can be achieved. The tensile tested $\mathrm{Al}_{2} \mathrm{O}_{3} / \mathrm{Ag} / \mathrm{l} n 49 \mathrm{Sn} / \mathrm{Ag} / \mathrm{Al}_{2} \mathrm{O}_{3}$ specimens fracture in the In49Sn matrix. However, as the $\mathrm{Ag}$ thick film is almost exhausted, cracking occurs along the interface between intermetallic compounds and alumina substrates, and the tensile strength of such an Ag/l n49Sn/Ag solder joint drops to a low value.

\section{REFERENCES}

1. D.R. Flanders, E.G. J acobes, and R.F. Pinizzotto, J . Electron. Mater. 26, 7 (1997).

2. L.H. Su, Y.W. Yen, C.C. Lin, and S.W. Chen, Metall. Mater. Trans. B 28B, 927 (1997).

3. S.K. Kang and Ramachandran, Scripta Metall. 14, 421 (1980).

4. V.I. Dybkov and O.V. Duchenko, J . Alloys Compounds 234, 295 (1996).

5. S. Choi, Y.R. Bieler, J .P. Lucas, and K.N. Subramanian, J . Electron. Mater. 28, 11 (1999).

6. H.K.Kim, H.K. Liou, and K.N.Tu, Appl. Phys. Lett. 66, 18 (1995).

7. H.K. Kim and K.N. Tu, Phys. Rev. B 53, 16027 (1996).

8. K.N. Tu and R.D Thompson, Acta Metall. 30, 947 (1982).

9. S. Bader and W. Gust, Acta Mater. Metall. 43, 1 (1995).

10. Y.T. Huang and T.H. Chuang, Z. Metallkd. 91, 12 (2000). 